\title{
MR-Eye: High-Resolution Microscopy Coil MRI for the Assessment of the Orbit and Periorbital Structures, Part 2: Clinical Applications
}

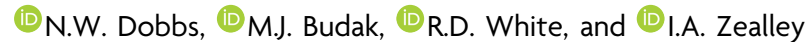

\begin{abstract}
SUMMARY: In the first part of this 2-part series, we described how to implement microscopy coil MR imaging of the orbits. Beyond being a useful anatomic educational tool, microscopy coil MR imaging has valuable applications in clinical practice. By depicting deep tissue tumor extension, which cannot be evaluated clinically, ophthalmic surgeons can minimize the surgical field, preserve normal anatomy when possible, and maximize the accuracy of resection margins. Here we demonstrate common and uncommon pathologies that may be encountered in orbital microscopy coil MR imaging practice and discuss the imaging appearance, the underlying pathologic processes, and the clinical relevance of the microscopy coil MR imaging findings.
\end{abstract}

ABBREVIATIONS: $\mathrm{BCC}=$ basal cell carcinoma; $\mathrm{MC}-\mathrm{MR}$ imaging $=$ microscopy coil MR imaging

$I^{n}$ the first part of this 2-part series, we described how to implement microscopy coil MR imaging (MC-MR imaging) of the orbits and described pearls and pitfalls of the technique that were acquired from experience at our institution (Ninewells Hospital, Dundee). We have demonstrated that submillimeter depiction of orbital structures using MC-MR imaging generates images that provide functional and clinically relevant anatomy of the orbit and orbital content.

As well as being a useful anatomic educational tool, MC-MR imaging has many applications in clinical practice. The key principle in ophthalmic surgery is to preserve vision. ${ }^{1}$ Preoperative imaging already aids this via its depiction of compartmental lesion location, guiding the most appropriate anatomic corridor to avoid manipulation of the optic and oculomotor nerves. ${ }^{1}$ With the superior tissue contrast that MC-MR imaging offers compared with conventional $\mathrm{MR}$ imaging and $\mathrm{CT},{ }^{2,3} \mathrm{MC}-\mathrm{MR}$ imaging increases confidence in lesion location and extent into different orbital compartments. Furthermore, by accurately demonstrating deep tissue tumor extension, the ophthalmic surgeons at our institution think they can better plan surgical procedures, preserving structures that

Received July 18, 2019; accepted after revision December 20, 2020.

From the Department of Clinical Neuroscience (N.W.D.), Royal Hospital for Children and Young People, Edinburgh, UK; Qscan Radiology Clinics (M.J.B.), Brisbane, Queensland, Australia; Department of Clinical Radiology (R.D.W.), University Hospital of Wales, Cardiff, UK; and Department of Clinical Radiology (I.A.Z.), Ninewells Hospital, Dundee, UK.

Please address correspondence to Nicholas W. Dobbs, MBBS, Department of Clinical Neuroscience, Royal Hospital for Children and Young People, Edinburgh, United Kingdom; e-mail: nicholas.dobbs@nhslothian.scot.nhs.uk

- Indicates open access to non-subscribers at www.ajnr.org

http://dx.doi.org/10.3174/ajnr.A7080 are difficult or impossible to reconstruct, while, at the same time, maximizing the accuracy of resection margins.

Furthermore, through an understanding of the orbital pathologies and their appearance on MC-MR imaging, a greater degree of confidence can be assured to diagnoses that are suspected clinically. This can help guide the surgeon and patient toward conservative management when appropriate, avoiding an inappropriate resection or damage to vital orbital structures or, conversely, demonstrate the need for more extensive resection when necessary. ${ }^{4}$ Although it may not always reveal additional information that would alter clinical management, MC-MR imaging will provide the radiologist and the surgeon with the highest resolution imaging of the pathology. By providing the highest resolution imaging the first time around, MC-MR imaging provides the best value to the patient by improving the clinician's confidence and minimizing the necessity for recalls and further clarification.

This article does not set out an exhaustive catalogue of orbital pathology but does provide examples that highlight the benefits of MC-MR imaging of the orbits. We describe common and uncommon pathologies that may be encountered in orbital MCMR imaging practice and discuss the imaging findings together with a description of the underlying pathologic processes and the clinical relevance of the MC-MR imaging findings.

\section{Basal Cell Carcinoma}

Basal cell carcinoma (BCC) is the most common skin malignancy, with its incidence rising with increasing age. ${ }^{5-7}$ Although the tumor only very rarely metastasizes, ${ }^{7}$ it is locally invasive, creating "rodent ulcers," which, with time, may become very large 

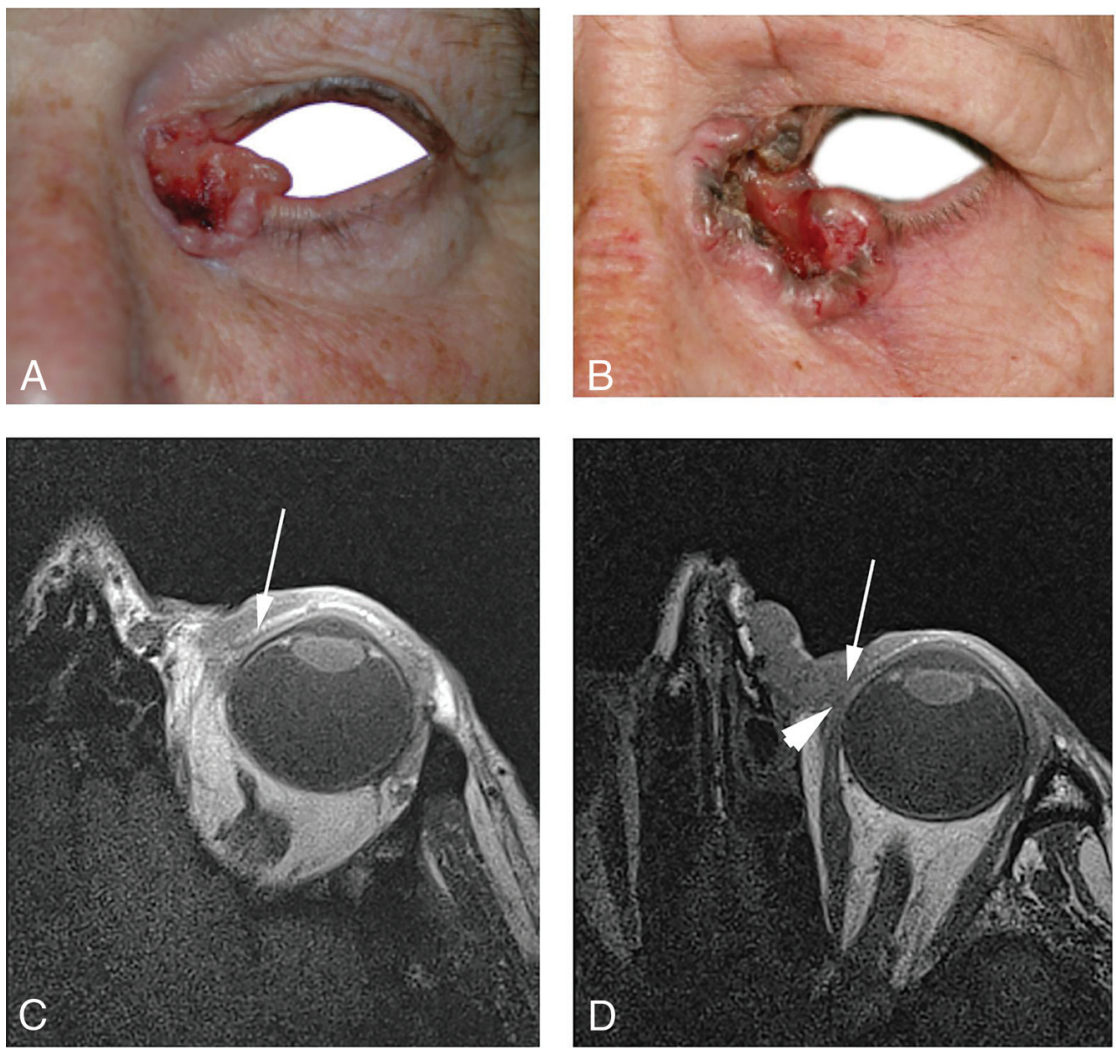

FIG 1. BCC of the left medial canthus in 2 elderly women. $A$, Clinical photograph of case 1. B, Clinical photograph of case 2 , which appears superficially similar to the first case. $C$, T1-weighted axial MC-MR imaging of case 1 demonstrates that the superior tarsal plate is intact (arrow) and not invaded by tumor. D, T1-weighted axial MC-MR imaging of case 2 demonstrates full-thickness tumor invasion of the superior tarsal plate (arrow), requiring complex oculoplastic reconstruction surgery to optimize eyelid function after resection of the tumor. The tumor also abuts the tendinous insertion of the medial rectus muscle (arrowhead), but there was no invasion of this found during the operation.

and invade critical deep structures. ${ }^{8-11}$ BCCs are associated with the stochastic effects of exposure to ultraviolet radiation, tending to occur in sun-exposed areas. ${ }^{7}$

The medial canthus of the eye is a common but sometimes surgically challenging site for BCC resection..$^{9,10,12,13}$ This issue is because the complex anatomy of the eyelids and tear ducts in this region may require complex reconstructive surgery ${ }^{10-12}$ and reliable clinical assessment of the deep lesion extent is impossible, ${ }^{10,11}$ with subclincal tumor extension being one of the main features found in recurrent BCC. ${ }^{14}$ When reporting MC-MR imaging, we accurately describe the extent of tissue invasion. This description allows preoperative planning of the surgical field, aiming to minimize the extent of surgery to preserve eye and tear duct function, while maximizing clear resection margins.

Invasion of the superior tarsal plate in the upper eyelid is a key determinant of the subsequent complexity of reconstruction. ${ }^{12,13,15}$ If this is spared, then surgical defects can usually be closed directly. ${ }^{12}$ However, if tarsal plate involvement mandates the creation of a full-thickness surgical defect, then the tarsal plate needs to be reconstructed. This reconstruction necessitates repair by oculoplastic surgeons using a variety of different techniques, including the Cutler-Beard bridge flap, in which conchal cartilage from the ear is grafted into the surgical defect to deliver the stability necessary for a functional eyelid. ${ }^{12,15,16}$ Tarsal plate invasion is difficult to determine clinically, as shown in Fig 1. However, involvement of the tarsal plate and other important structures is exquisitely depicted on T1-weighted MC-MR imaging sequences, allowing advanced surgical planning to ensure that appropriately skilled surgical personnel are present for reconstruction and wound closure.

\section{Dermoid Cyst}

Dermoid cysts are benign lesions that arise from rests of embryonic epithelium, which are abnormally sequestered into embryologic sites of fusion and may be encountered as incidental findings. ${ }^{17,18}$ However, they may present due to cyst growth causing mass effect or following cyst rupture and subsequent induction of a local inflammatory response. ${ }^{17,19}$

Dermoid cysts are lined by squamous epithelium and may also contain skin appendages, including hair follicles, sebaceous glands, and sweat glands, features that differentiate dermoid from epidermoid cysts. ${ }^{18,20}$ These pathologic features are mirrored in the imaging, with MC-MR imaging demonstrating a well-defined, extraconal mass with components of varying signal return depending on their contents. Most telling is the sebumrich component, which returns high signal on T1-weighted imaging, with signal drop-out on fat-saturated T1-weighted imaging. ${ }^{21}$ This appearance is demonstrated in Fig 2.

Surgical treatment for orbital dermoid cysts is primarily cosmetic, usually to reduce the degree of proptosis associated with the mass effect. Surgery is also indicated when the mass impairs eye movement or when rupture causes orbital inflammation. ${ }^{22}$ MC-MR imaging is useful for preoperative planning through its demonstration of deep lesion extent; superficial lesions can be easily and completely excised, whereas deep lesions may require complex deep orbital dissection. ${ }^{22-24}$

\section{Melanoma}

Uveal melanoma is the most common intraocular malignant tumor of adulthood. ${ }^{25,26}$ Nevertheless, it remains relatively uncommon, with an annual incidence of 6 per million population. ${ }^{25,27}$ Diagnosis and staging of uveal melanoma are usually purely clinical, with the use of ophthalmoscopy and slit lamp biomicroscopy. ${ }^{26,28}$ However, when there is secondary orbital melanoma, either as local spread or recurrence or as a true metastasis, imaging with MC-MR imaging can add value. ${ }^{29,30}$ 

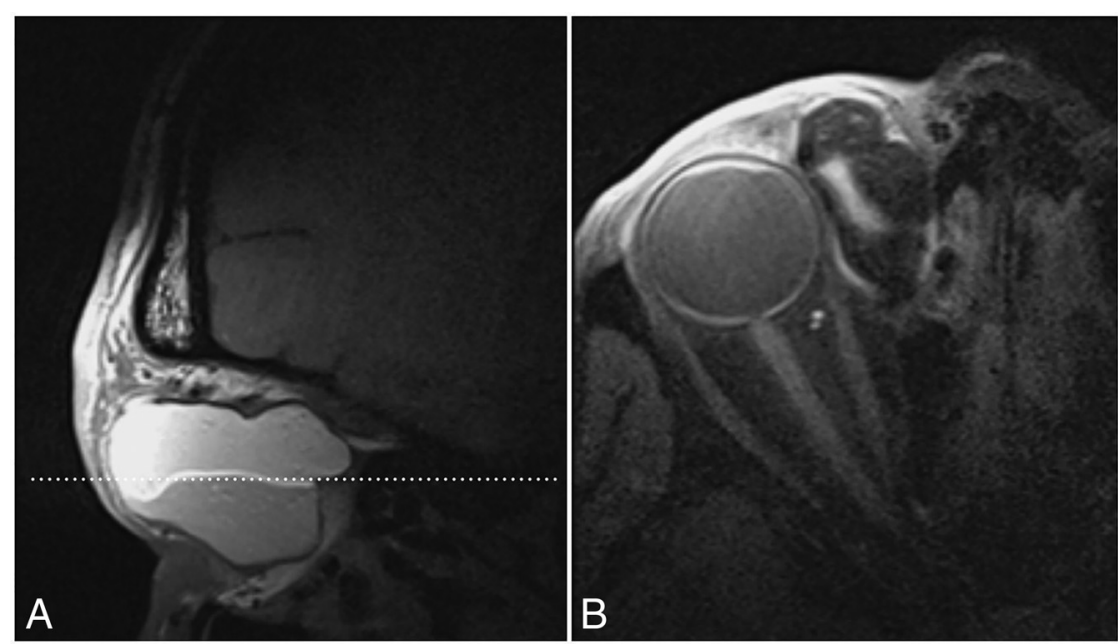

FIG 2. Dermoid cyst in the superonasal quadrant of the orbit in a 46-year-old man who had presented with slowly progressive swelling on the medial aspect of the right globe. A, T1-weighted sagittal MC-MR imaging demonstrates a superior layer of high signal intensity and an inferior layer of lower intensity. The acquisition plane of $B$ is denoted by the dotted line. B, Fat-saturated T1weighted axial MC-MR imaging shows signal drop-out of the superior layer, confirming fat content and reinforcing the preoperative diagnosis of dermoid cyst.
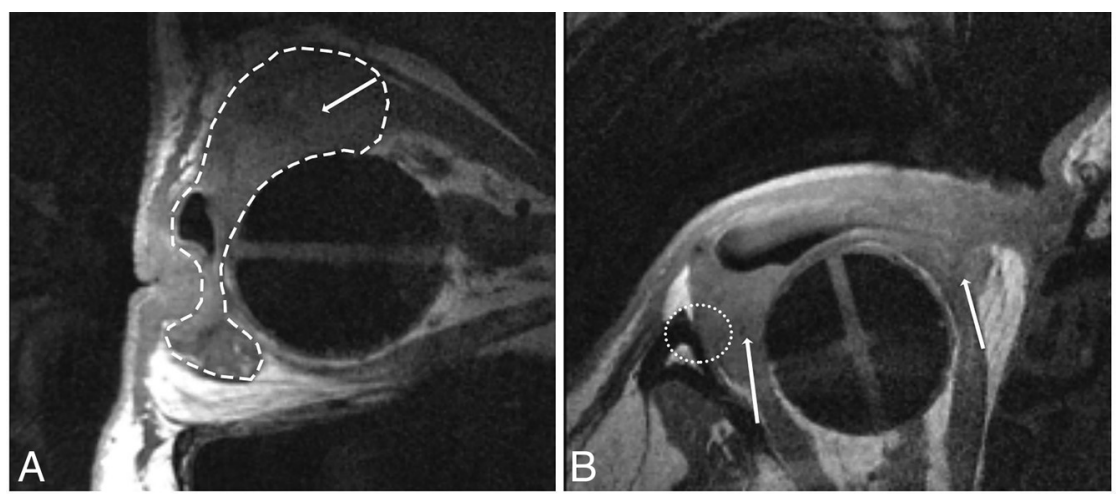

FIG 3. Intraorbital melanoma metastasis in an elderly woman with previous enucleation for primary iris melanoma.T1-weighted sagittal MC-MR imaging $(A)$ and T1-weighted axial MC-MR imaging $(B)$ demonstrate a bilobed mass (dashed white line) involving the extraocular muscles (arrows) and abutting the periosteum of the lateral orbital wall (dotted white circle). The tarsal plate was also invaded. Surgical resection margins were planned accordingly, with clear margins confirmed on histologic examination of the resection specimen.

Secondary orbital melanoma has a propensity to involve the extraocular muscles. ${ }^{29-31}$ The detailed depiction of the extent of tumor invasion provided by MC-MR imaging facilitates surgical planning to ensure full clearance. The case shown in Fig 3 demonstrates periosteal involvement, and surgical margins were adjusted accordingly.

\section{Lacrimal Gland Prolapse}

The lacrimal glands contain both lymphoid and epithelioid tissues and so may be affected by a diverse range of pathologic processes. ${ }^{32}$ The presentation of lacrimal disorders typically involves nonspecific swelling of the outer aspect of the upper eyelid; clarifying the cause of localized palpebral swelling on clinical grounds alone is challenging. ${ }^{32,33}$ We have found that MC-MR imaging can assist with diagnosis and devising appropriate treatment, including the planning of surgical excision when appropriate.

An interesting and unusual lacrimal cause of lateral upper eyelid swelling is a prolapse of otherwise-normal lacrimal tissue, surrounded by fat, under the superior orbital rim. While this is a relatively reassuring diagnosis, the surgical management of lacrimal gland prolapse can be challenging. Macroscopically, the prolapsed lacrimal tissue resembles hypertrophied fat, which can lead to an inadvertent lacrimal resection during blepharoplasty, with subsequent aqueous tear deficiency and resultant damage to the surface of the eye. ${ }^{34,35}$ MC-MR imaging evaluation of palpebral swelling can alert ophthalmic surgeons to this diagnosis, as was the case in Fig 4, and help avoid inadvertent lacrimal gland resection.

\section{Venous Malformation}

Venous malformations, previously known as cavernous malformations, are the most common orbital vascular lesions of adulthood. Typically, they present with painless proptosis or may occasionally be diagnosed as an incidental finding on head imaging for other indications. ${ }^{36}$

Rapidly progressive proptosis due to a venous malformation has been described in both puberty and pregnancy. ${ }^{37}$ The accelerated growth of the malformations in pregnancy has been attributed to the increase in serum concentrations of vascular endothelial growth factor, which occurs with the progression of pregnancy, because immunohistochemical studies have shown that venous malformations express vascular endothelial growth factor receptors. ${ }^{38}$ These observations support the hypothesis of a hormone-driven and angiogenic cytokine-mediated growth pattern. ${ }^{36}$

The nature of the underlying pathologic processes that lead to the development of venous malformations is a controversial topic, with some sources postulating a purely venous origin while others suggest that they are a form of low-flow arteriovenous malformation with a fibrous pseudocapsule. ${ }^{36,39,40}$ Nevertheless, they have a characteristic appearance that facilitates the radiologic diagnosis. They are typically well-defined, lobulated masses, with signal isointense to muscle on T1-weighted acquisitions and hyperintense to muscle on T2-weighted acquisitions. This appearance is demonstrated in Fig 5. 

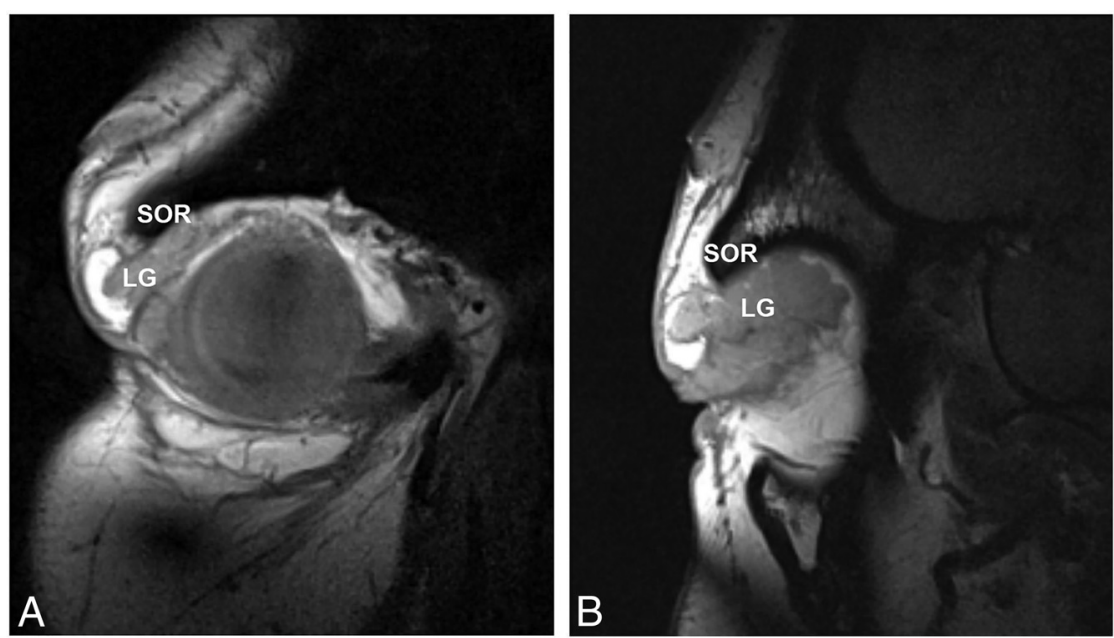

FIG 4. Lacrimal gland prolapse in a 27-year-old woman who had presented with palpebral swelling of uncertain origin. T-weighted coronal MC-MR imaging $(A)$ and TT-weighted sagittal MC-MR imaging $(B)$ demonstrate prolapse of the lacrimal gland (LG) under the superior orbital rim (SOR). The patient was reassured and discharged from the clinic. Should future blepharoplasty be considered, intraoperative repositioning of the gland would be incorporated into the surgical planning. ${ }^{16}$
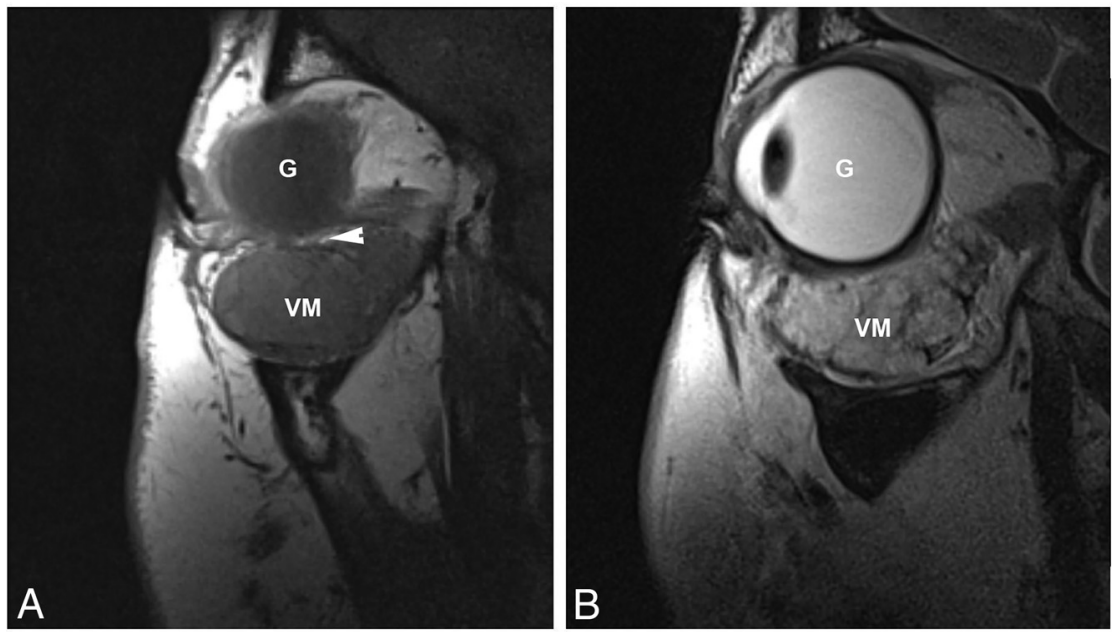

FIG 5. Venous malformation in a middle-aged woman. Tl-weighted sagittal MC-MR imaging $\mathrm{Tl}(A)$ and T2-weighted sagittal MC-MR imaging (B) demonstrate a well-defined, lobulated mass (VM) with signal isointense to muscle on T1-weighted acquisitions and signal hyperintense to muscle on T2-weighted acquisitions. A clean fat plane (arrowhead) separates the lesion from the globe (G), in keeping with a fibrous pseudocapsule. Such narrow fat planes would not be resolved on head coil MR imaging. Despite close proximity, neither the rectus muscles nor the tarsal plate was involved, and the lesion was surgically removed intact.

\section{Lymphatic Malformation}

Lymphatic malformations are benign lesions that tend to be diagnosed in early childhood. They are nonencapsulated and consist of multiple lymph-filled channels of various caliber, separated by fine septa. ${ }^{36}$ As slow-growing lesions, they usually present with gradual onset and progressive proptosis but can present with more sudden proptosis in the case of intralesional hemorrhage. ${ }^{41}$ Management is often conservative, and traditionally surgery was considered when the degree of proptosis caused distress on cosmetic grounds or if the intraorbital involvement impaired eye movement and visual acuity. However, the lesions often insinuate between the compartments of the orbit and can be intricately related to the extraocular muscles and optic nerve. This feature makes complete surgical excision challenging, with recurrence common. ${ }^{36,41}$ Thus, percutaneous sclerotherapy is now thought an excellent treatment option for the condition because it has been shown to be safe and effective. ${ }^{41}$ In Fig 6, a recurrent lymphatic malformation is demonstrated, with MC-MR imaging as part of the work-up before bleomycin sclerotherapy.

\section{Summary}

Cross-sectional imaging is already in use for orbital abnormalities, ${ }^{27,36}$ and MC-MR imaging of the orbits has been previously described but with rather limited clinical application. ${ }^{2,42-44}$ However, the high spatial resolution of MC-MR imaging facilitates assessment of lesions and their relationship to normal anatomic structures in detail sufficient to more confidently and accurately guide the therapeutic approach. MC-MR imaging is particularly valuable for depicting tumor invasion of critical small structures such as the tarsal plates and for depicting clean fat planes between important structures or obliteration of these planes due to tumor invasion. Thus, MC-MR imaging can be implemented for imaging of orbital mass lesions in routine clinical practice. Furthermore, while diagnoses are usually established on clinical grounds, we have observed that characteristic MC-MR imaging appearances of several orbital pathologies can facilitate diagnosis in some unusual cases.

The added value of MC-MR imaging over conventional MR imaging is clear in many of the cases presented. We accept that in some cases, patients would have been managed appropriately with conventional CT or MR imaging. However, until an imaging investigation is performed, it may not be clear whether a particular case will benefit from high-resolution imaging. We are aware of the need to provide the best value for patients. We suggest that by performing MC-MR imaging as the first-line investigation, we are delivering the best value to patients by providing the highest resolution imaging the first time around and avoiding the delay, inconvenience, and expense of recalls for clarification. Furthermore, the surgeons 

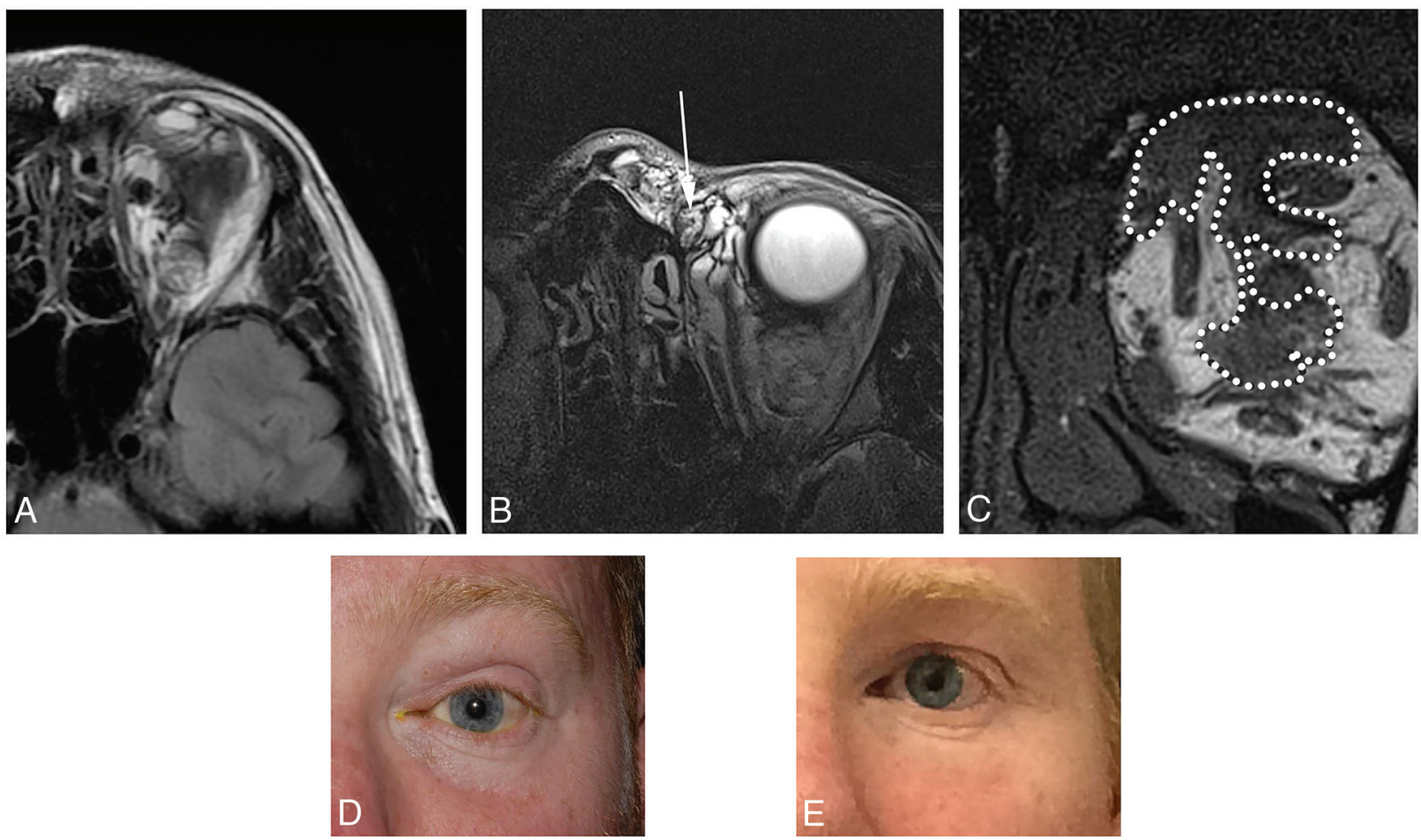

FIG 6. A persistent lymphatic malformation in a middle-aged man who had undergone multiple previous operations and steroid injections. MCMR imaging was performed to guide definitive management. A, Conventional head coil T2-weighted axial MR imaging demonstrates the lymphatic malformation, but the clarity of depiction of the lesion margins and relationships is insufficient to guide treatment. T2-weighted axial MC-MR imaging (B) demonstrates the lesion's characteristic appearance (arrow) and Tl-weighted coronal MC-MR imaging (C) demonstrates the lesion (dotted white line) extending from the periorbital soft tissues into the orbit and intraconally, an extent of involvement that precludes safe surgical intervention. Consequently, bleomycin sclerotherapy was performed with pretreatment $(D)$ and posttreatment photography (with the patient's permission) (E) demonstrating aesthetic improvement.

with whom we work have become accustomed to high-resolution MC-MR imaging of orbital pathologies and indicate that they find that these images allow them to better visualize what they will encounter at the operation and how best to plan their procedures.

As well as providing a descriptive radiologic report, we encourage review of the images alongside the ophthalmic, oculoplastic, or dermatologic surgeons. This collegial approach helps the radiologist understand the clinically and surgically pertinent findings and helps the surgeon by delineating the often-complex anatomic relationships between orbital lesions and surrounding structures. This close clinical liaison builds a mutually beneficial interdisciplinary relationship and increases the appropriateness and utility of referrals for MC-MR imaging, leading to better informed treatment plans and optimization of patient outcomes.

Disclosures: Ian A. Zealley-UNRELATED: Employment: National Health Service Tayside, Comments: This is the health service that employs me to perform clinical work. Expert Testimony: legal firms, Comments: expert opinion provided in relation to litigation not related to the work presented for publication; Travel/ Accommodations/Meeting Expenses Unrelated to Activities Listed: various medical education meetings, Comments: support from meeting organizers to present lectures on various subjects.

\section{REFERENCES}

1. Paluzzi A, Gardner PA, Fernandez-Miranda JC, et al. "Round-theClock" surgical access to the orbit. J Neurol Surg B Skull Base 2015;76:12-24 CrossRef Medline
2. Georgouli T, James T, Tanner S, et al. High-resolution microscopy coil MR-Eye. Eye (Lond) 2008;22:994-96 CrossRef Medline

3. Budak MJ, Weir-Mccall JR, Yeap PM, et al. High-resolution microscopy-coil MR imaging of skin tumors: techniques and novel clinical applications. Radiographics 2015;35:1077-90 CrossRef Medline

4. Lin LK, Reznick A, Mukundan G, et al. Pictorial review of histopathologically diagnosed orbital tumors. American Journal of Ophthalmic Clinical Trails 2019;2:1-9 CrossRef

5. Reinau D, Surber C, Jick SS, et al. Epidemiology of basal cell carcinoma in the United Kingdom: incidence, lifestyle factors, and comorbidities. Br J Cancer 2014;111:203-06 CrossRef Medline

6. Apalla Z, Lallas A, Sotiriou E, et al. Epidemiological trends in skin cancer. Dermatol Pract Concept 2017;7:1-6 CrossRef Medline

7. Kim DP, Kus KJ, Ruiz E. Basal cell carcinoma review. Hematol Oncol Clin North Am 2019;33:13-24 CrossRef Medline

8. Kasper M, Jaks V, Hohl D, et al. Basal cell carcinoma: molecular biology and potential new therapies. J Clin Invest 2012;122:455-63 CrossRef Medline

9. Shi Y, Jia R, Fan X. Ocular basal cell carcinoma: a brief literature review of clinical diagnosis and treatment. Onco Targets Ther 2017;10:2483-89 CrossRef Medline

10. Slutsky JB, Jones EC. Periocular cutaneous malignancies: a review of the literature. Dermatol Surg 2012;38:552-69 CrossRef Medline

11. Leibovitch I, McNab A, Sullivan T, et al. Orbital invasion by periocular basal cell carcinoma. Ophthalmology 2005;112:717-23 CrossRef Medline

12. Ahmad J, Mathes DW, Itani KM. Reconstruction of the eyelids after Mohs surgery. Semin Plast Surg 2008;22:306-18 CrossRef Medline

13. Actis AG, Actis G. Reconstruction of the upper eyelid with flaps and free grafts after excision of basal cell carcinoma. Case Rep Ophthalmol 2011;2:347-53 CrossRef Medline 
14. Malhotra R, Huilgol SC, Huynh NT, et al. The Australian Mohs database, Part I: periocular basal cell carcinoma experience over 7 years. Ophthalmology 2004;111:624-30 CrossRef Medline

15. Irvine $\mathrm{F}, \mathrm{McNab} \mathrm{AA}$. Technique for reconstruction of upper lid marginal defects. Br J Ophthalmol 2003;87:279-81 CrossRef Medline

16. Cutler NL, Beard C. A method for partial and total upper lid reconstruction. Am J Ophthalmol 1955;39:1-7 CrossRef Medline

17. Shields JA, Kaden IH, Eagle RC, et al. Orbital Dermoid Cysts: Clinicopathologic Correlations, Classification, and Management: The 1997 Josephine E. Schueler Lecture. Ophthalmic Plast Reconstr Surg 1997;13:265-76 CrossRef Medline

18. Shields JA, Shields CL. Orbital cysts of childhood-classification, clinical features, and management. Surv Ophthalmol 2004;49:28199 CrossRef Medline

19. Bonavolontà G, Tranfa F, de Conciliis C, et al. Dermoid cysts: 16year survey. Ophthalmic Plast Reconstr Surg 1995;11:187-92 CrossRef Medline

20. Smirniotopoulos JG, Chiechi MV. Teratomas, dermoids, and epidermoids of the head and neck. Radiographics 1995;15:1437-55 CrossRef Medline

21. Chung EM, Murphey MD, Specht CS, et al. From the Archives of the AFIP; Pediatric orbit tumors and tumorlike lesions: osseous lesions of the orbit. Radiographics 2008;28:1193-1214 CrossRef Medline

22. Chaudhry IA. Management of deep orbital dermoid cysts. Middle East Afr J Ophthalmol 2008;15:43-45 CrossRef Medline

23. Lane CM, Ehrlich WW, Wright JE. Orbital dermoid cyst. Eye (Lond) 1987;1(Pt 4):504-11 CrossRef Medline

24. Cavazza S, Laffi GL, Lodi L, et al. Orbital dermoid cyst of childhood: clinical pathologic findings, classification and management. Int Ophthalmol 2011;31:93-97 CrossRef Medline

25. Egan KM, Seddon JM, Glynn RJ, et al. Epidemiologic aspects of uveal melanoma. Surv Ophthalmol 1988;32:239-51 CrossRef Medline

26. Mellen PL, Morton SJ, Shields CL. American Joint Committee on Cancer Staging of Uveal Melanoma. Oman J Ophthalmol 2013;6:11618 CrossRef Medline

27. Tailor TD, Gupta D, Dalley RW, et al. Orbital neoplasms in adults: clinical, radiologic, and pathologic review. Radiographics 2013;33:1739-58 CrossRef Medline

28. Shields JA, Shields CL, De Potter P, et al. Diagnosis and treatment of uveal melanoma. Semin Oncol 1996;23:763-67 Medline

29. Rosenberg C, Finger PT. Cutaneous malignant melanoma metastatic to the eye, lids, and orbit. Surv Ophthalmol 2008;53:187-202 CrossRef Medline
30. Rose AM, Cowen S, Jayasena CN, et al. Presentation, treatment, and prognosis of secondary melanoma within the orbit. Front Oncol 2017;7:125 CrossRef Medline

31. Conill C, Morilla I, Malvehy J, et al. Secondary orbital metastases from cutaneous melanoma. Melanoma Res 2004;14:437-38 CrossRef Medline

32. Hughes GK, Miszkiel KA. Imaging of the lacrimal gland. Semin Ultrasound CT MR 2006;27:476-91 CrossRef Medline

33. Mohan S, Hegde A, Tchoyoson Lim CC. Lacrimal glands: size does matter! Middle East Afr J Ophthalmol 2011;18:328-30 CrossRef Medline

34. Massry GG. Prevalence of lacrimal gland prolapse in the functional blepharoplasty population. Ophthalmic Plast Reconstr Surg 2011;27:410-13 CrossRef Medline

35. Hundal KS, Mearza AA, Joshi N. Lacrimal gland prolapse in blepharochalasis. Eye (Lond) 2004;18:429-30 CrossRef Medline

36. Smoker WR, Gentry LR, Yee NK, et al. Vascular lesions of the orbit: more than meets the eye. Radiographics 2008;28:185-204; quiz 325 CrossRef Medline

37. Zauberman $\mathrm{H}$, Feinsod M. Orbital hemangioma growth during pregnancy. Acta Ophthalmol (Copenh) 1970;48:929-33 CrossRef Medline

38. Nagasaka M, Naganuma H, Satoh E. Growth potential of orbital cavernous hemangioma suggested by vascular endothelial growth factor and its receptor flk-1. Neurol Med Chir (Tokyo) 2007;47:5-10 CrossRef Medline

39. Ansari SA, Mafee MF. Orbital cavernous hemangioma: role of imaging. Neuroimaging Clin N Am 2005;15:137-58 CrossRef Medline

40. Rootman J. Vascular malformations of the orbit: hemodynamic concepts. Orbit 2003;22:103-20 CrossRef Medline

41. Barnacle AM, Theodorou M, Maling SJ, et al. Sclerotherapy treatment of orbital lymphatic malformations: a large single-centre experience. Br J Ophthalmol 2016;100:204-08 CrossRef Medline

42. Hoffmann KT, Hosten N, Lemke AJ, et al. Septum orbitale: high-resolution MR in orbital anatomy. AJNR Am J Neuroradiol 1998;19:91-94 Medline

43. Kau HC, Tsai CC, Ortube MC, et al. High-resolution magnetic resonance imaging of the extraocular muscles and nerves demonstrates various etiologies of third nerve palsy. Am J Ophthalmol 2007;143:280-87 CrossRef Medline

44. Clark RA, Demer JL. Magnetic resonance imaging of the globe-tendon interface for extraocular muscles: is there an "arc of contact"? Am J Ophthalmol 2018;194:170-81 CrossRef Medline 